\title{
Predicting power output of photovoltaic systems with solar radiation model
}

\begin{abstract}
Predicting of solar resource in general is momentous for preparation of the operations of power plants which transform renewable energies to electricity. In particular, the possibility to predict the solar irradiance (up to one day or even more) can become of significant interest with reference to Grid connected Photovoltaic (PV) Plants, stand alone and hybrid system. In this paper, a MATLAB/SIMULINK simulation based model for predicting hourly solar radiation using modified Hottel's radiation model is presented. The proposed modified Hottel's model makes it possible to predict solar radiation on hourly basis using current values of day type and geography of the location. While predicting power output, the model requires information of the weather forecast of the day to be predicted, some data from solar module datasheet is use and predicted radiation. The predicted results are compared with outdoor data collected by horizontal mount pyranometer at coordinates $(2.945 \mathrm{~N}, 101.728 \mathrm{E})$ on 24th, June 2012. The results indicated the proposed model performed well after comparison with field data, having a correlation coefficient of $97 \%$, also recorded $96 \%$ and 76\% with Hottel's and Ashrae model respectively.
\end{abstract}

Keyword: Prediction; Photovoltaic systems; Power; Solar radiation 